\title{
AWARENESS ON RISK FACTORS AND WARNING SIGNS OF STROKE AMONG INDIVIDUALS WITH HYPERTENSION
}

\author{
Veena Jasmine Pinto ${ }^{1}$, Peter George ${ }^{2}$
}

${ }^{1}$ Assistant Professor, Department of General Medicine, Father Muller Medical College, Mangaluru, South India.

2Professor, Department of General Medicine, Father Muller Medical College, Mangaluru, South India.

\begin{abstract}
BACKGROUND

Incidence of stroke and its associated mortality is rising in India. Awareness of the risk factors and warning signs of stroke ensures early diagnosis and prompt interventions with better outcome. We have tried to identify the awareness of risk factors and warning signs of stroke in individuals with hypertension.

Aims- 1 To assess the awareness on risk factors of stroke among individuals with hypertension. 2 To assess the knowledge on warning signs of stroke among individuals with hypertension.
\end{abstract}

\section{MATERIALS AND METHODS}

This descriptive cross sectional study was conducted at a tertiary care hospital in Southern India. Total of 200 individuals with hypertension were randomly selected and a closed-ended questionnaire was administered in a face-to-face interview. The data collected were tabulated and analysed using SPSS version-23.

\section{RESULTS}

Among the 200 hypertensive subjects, there were 113 males (56.5\%) and 87 females (43.5\%). In this study, 85\% identified > 4 risk factors and 59.5\% recognised $>4$ warning signs of stroke. Hypertension was the most frequently recognised risk factor (94\%) followed by lack of exercise (82.5\%), smoking (81.5\%), Diabetes Mellitus (75\%) and stress (73\%). Facial deviation was identified as a stroke warning sign by $96 \%$ of subjects. Subjects with younger age, higher educational level and higher income had a statistical significant ( $p$ - value $<0.05$ ) awareness on risk factors and warning signs of stroke.

\section{CONCLUSION}

The awareness of risk factors and warning signs of stroke was found to be good among subjects with hypertension. Health care providers have an important role in educating the public on various aspects of stroke prevention.

\section{KEYWORDS}

Stroke, Awareness, Hypertension, Risk Factors, Warning Signs, Southern India.

HOW TO CITE THIS ARTICLE: Pinto VJ, George P. Awareness on risk factors and warning signs of stroke among individuals with hypertension. J. Evolution Med. Dent. Sci. 2017;6(30):2410-2414, DOI: 10.14260/Jemds/2017/520

\begin{abstract}
BACKGROUND
Stroke is amongst the three leading causes of death and the most frequent cause for disability in adults. ${ }^{1}$ The incidence of stroke and associated mortality are higher in India as compared to the Western world. ${ }^{2-4}$ Early warning signs of stroke such as weakness or numbness of face or limb on one side, difficulty in talking, vision alteration, dizziness and sudden headache are easily recognisable. Individuals with hypertension, diabetes mellitus, ischaemic heart disease, dyslipidaemia or smoking are at high risk for developing stroke. Knowledge on risk factors and warning signs of stroke among such high-risk individuals may help them seek early medical attention with good clinical outcomes. Among risk factors for stroke, hypertension has the highest relative risk of 2-5 to develop stroke.
\end{abstract}

Financial or Other, Competing Interest: None.

Submission 14-03-2017, Peer Review 31-03-2017,

Acceptance 05-04-2017, Published 13-04-2017.

Corresponding Author:

Dr. Veena Jasmine Pinto,

Assistant Professor,

Department of General Medicine,

Father Muller Medical College,

Mangaluru-575002, South India.

E-mail:vj17pinto@yahoo.com

DOI: $10.14260 /$ jemds $/ 2017 / 520$
In India, the awareness of risk factors and warning signs of stroke in general population is found to be poor. ${ }^{5,6}$ Studies from India have assessed stroke awareness among hypertensive patients with one from Southern India. ${ }^{7}$ In this study, we have assessed the awareness on risk factors and warning signs of stroke among individuals with hypertension.

\section{Aims and Objectives}

1. To assess the awareness on risk factors of stroke among individuals with hypertension.

2. To assess the knowledge on warning signs of stroke among individuals with hypertension.

\section{MATERIALS AND METHODS}

This is a descriptive cross sectional study, conducted over 2 months from $1^{\text {st }}$ September 2016, among individuals with hypertension. After obtaining the Institutional Ethics Committee approval, individuals with hypertension were randomly selected from the out-patient and in-patient services of a Tertiary Care Hospital in Mangaluru, Southern India.

The questionnaire used was adapted from Borhani Haghighi et al. 8 This was earlier modified and validated for an Indian study in general population. 6 Individuals who fulfilled the selection criteria were included to the study after obtaining a written informed consent. The investigators then 
administered the questionnaire to the subjects through a face-to-face interview. The required description of every question was made for their clear understanding. The responses were captured in a blinded response sheet. The questionnaire consisted of 40 questions, which were divided in three sections-

1. Demographic profile with 8 questions,

2. Risk factors of stroke with 19 questions and

3. Warning signs of stroke with 13 questions. The second and third sections contained structured questions with 'yes' or 'no' responses.

\section{Inclusion Criteria}

1. Individuals diagnosed to have hypertension.

2. Individuals on treatment for hypertension.

\section{Exclusion Criteria}

1. Individuals with previous stroke/TIA.

2. Individuals with family members having stroke.

3. Health care professionals.

Descriptive and comparative statistical analysis were done using SPSS version-23. The demographic profile, awareness of risk factors and warning signs of stroke were analysed using frequencies and percentages. To identify the relationship between demographic characteristics and stroke awareness; Chi-square test and Fisher's exact test were used. A p- value of $<0.05$ was considered to be significant.

\section{RESULTS}

This study was done on 200 subjects having hypertension; there were 113 males (56.5\%) and 87 females (43.5\%).

\begin{tabular}{|c|c|c|c|}
\hline \multicolumn{2}{|c|}{ Characteristics } & $\begin{array}{c}\text { Numbers } \\
\text { (n) }\end{array}$ & $\begin{array}{c}\text { Percentage } \\
(\%)\end{array}$ \\
\hline \multirow{3}{*}{ Age groups } & $<45$ years & 5 & 2.5 \\
\hline & $45-65$ years & 151 & 75.5 \\
\hline & $>65$ years & 44 & 22.0 \\
\hline \multirow[t]{2}{*}{ Gender } & Female & 87 & 43.5 \\
\hline & Male & 113 & 56.5 \\
\hline \multirow[t]{2}{*}{ Location } & Urban & 102 & 51.0 \\
\hline & Rural & 98 & 49.0 \\
\hline \multirow{4}{*}{ Education } & No formal education & 7 & 3.5 \\
\hline & Primary education & 59 & 29.5 \\
\hline & Secondary education & 84 & 42.0 \\
\hline & Degree \& above & 50 & 25.0 \\
\hline \multirow{4}{*}{$\begin{array}{l}\text { Income } \\
\text { (INR) }\end{array}$} & No income & 56 & 28.0 \\
\hline & $<10000$ & 43 & 21.5 \\
\hline & $10000-20000$ & 74 & 37.0 \\
\hline & $>20000$ & 27 & 13.5 \\
\hline \multirow{3}{*}{$\begin{array}{c}\text { Duration of } \\
\text { Hyper- } \\
\text { Tension } \\
\text { (years) }\end{array}$} & Up to 3 & 42 & 21.0 \\
\hline & $3-5$ & 66 & 33.0 \\
\hline & Above 5 & 92 & 46.0 \\
\hline
\end{tabular}

The demographic characteristics of the subjects are listed in Table-1. Among the subjects, $75.5 \%$ (n: 151) were in the age group of 45 to 65 years. Also, 51\% (n: 102) of our subjects were from urban dwellings. Interestingly, 67\% (n: 134) of subjects completed their secondary education or above; and a mere $3.5 \%$ were uneducated. Subjects with duration of hypertension > 5 years were $46 \%$ (n: 92) and between 3 to 5 years were $33 \%$ (n: 66).
Awareness on risk factors of stroke is represented in Table-2 as frequencies and percentages. In this study, 85\% (n: 170) identified $>4$ risk factors and 15\% (n: 30) identified 3-4 risk factors. Most frequently identified risk factors for stroke were hypertension (94\%), lack of exercise $(82.5 \%)$, smoking (81.5\%), Diabetes Mellitus (75\%) and stress (73\%).

\begin{tabular}{|c|c|c|}
\hline Risk Factor & $\begin{array}{l}\text { Frequency } \\
\text { (n) }\end{array}$ & $\begin{array}{l}\text { Percentage } \\
\quad(\%)\end{array}$ \\
\hline Hypertension & 188 & 94.0 \\
\hline Systolic BP & 44 & 22.0 \\
\hline Diastolic BP & 16 & 8.0 \\
\hline BP control for prevention & 175 & 87.5 \\
\hline Arrhythmia & 33 & 16.5 \\
\hline Exercise & 165 & 82.5 \\
\hline Obesity & 101 & 50.5 \\
\hline Smoking & 163 & 81.5 \\
\hline Hypercholesterolaemia & 113 & 56.5 \\
\hline Diabetes Mellitus & 150 & 75.0 \\
\hline Dietary habits & 118 & 59.0 \\
\hline Family history & 92 & 46.0 \\
\hline Hypertriglyceridaemia & 79 & 39.5 \\
\hline Prior MI & 38 & 19.0 \\
\hline DM control for prevention & 158 & 79.0 \\
\hline Stress & 146 & 73.0 \\
\hline Unpreventable & 85 & 42.5 \\
\hline $\begin{array}{c}\text { Number of Risk Factors } \\
\text { Identified }\end{array}$ & Frequency & Percentage \\
\hline $3-4$ & 30 & 15 \\
\hline$>4$ & 170 & 85 \\
\hline \multicolumn{3}{|c|}{$\begin{array}{c}\text { Table 2. Frequency and Percentage of Correct Response to } \\
\text { Questions on Stroke Risk Factors }\end{array}$} \\
\hline
\end{tabular}

Awareness on other risk factors such as dietary habits, high cholesterol, obesity and family history were 59\%, 56.5\%, $50.5 \%$ and $46 \%$ respectively. Knowledge about previous MI (19\%) and arrhythmia (16.5\%) as risk factors for stroke were found to be poor. Control of hypertension and diabetes mellitus for prevention of stroke were identified by $87.5 \%$ and $79 \%$ of subjects. Interestingly, $42.5 \%$ of the subjects found stroke to be unpreventable disease.

\begin{tabular}{|c|c|c|}
\hline Warning sign & Frequency & Percentage \\
\hline Body pain & 115 & $57.5 \%$ \\
\hline One-sided weakness & 146 & $73.0 \%$ \\
\hline Paraesthesia & 87 & $43.5 \%$ \\
\hline Chest pain & 75 & $37.5 \%$ \\
\hline Abdominal discomfort & 32 & $16.0 \%$ \\
\hline Difficulty in talking & 161 & $80.5 \%$ \\
\hline Facial deviation & 192 & $96.0 \%$ \\
\hline Vertigo & 92 & $46.0 \%$ \\
\hline Altered vision & 86 & $43.0 \%$ \\
\hline Ataxia & 85 & $42.5 \%$ \\
\hline Dyspnoea & 69 & $34.5 \%$ \\
\hline Headache & 69 & $34.5 \%$ \\
\hline Altered consciousness & 129 & $64.5 \%$ \\
\hline $\begin{array}{c}\text { Number of warning signs } \\
\text { identified }\end{array}$ & Frequency & Percentage \\
\hline $1-2$ & 12 & 6.0 \\
\hline $3-4$ & 69 & 34.5 \\
\hline$>4$ & 119 & 59.5 \\
\hline \multicolumn{3}{|c|}{$\begin{array}{l}\text { Table 3. Frequency and Percentage of Responses to } \\
\text { Questions on Stroke Warning Signs }\end{array}$} \\
\hline
\end{tabular}


Awareness on warning signs of stroke is shown in Table3. Subjects identifying $>4$ warning signs of stroke were $59.5 \%$; and $6 \%$ were aware of only 1 or 2 warning signs. Facial deviation was identified by $96 \%$ as most frequent warning sign; followed by difficulty in talking (80.5\%), onesided limb weakness (73\%) and altered consciousness (64\%). Awareness on warning signs such as paraesthesia (43.5\%), vertigo (46\%), ataxia (42.5\%) and headache (34.5\%) were found to be poor.

\begin{tabular}{|c|c|c|c|c|c|c|}
\hline \multirow{3}{*}{\multicolumn{2}{|c|}{ 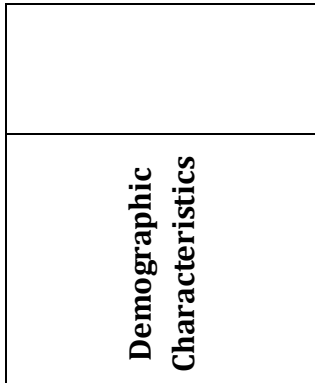 }} & \multicolumn{4}{|c|}{$\begin{array}{l}\text { Number of Stroke Risk } \\
\text { Factors Identified }\end{array}$} & \multirow[b]{3}{*}{$\begin{array}{l}\stackrel{0}{\Xi} \\
\frac{\pi}{\pi} \\
\dot{2} \\
2\end{array}$} \\
\hline & & \multicolumn{2}{|c|}{$3-4$} & \multicolumn{2}{|c|}{$>4$} & \\
\hline & & 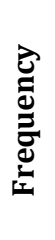 & $\partial^{e}$ & 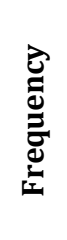 & $\delta^{0}$ & \\
\hline \multirow{3}{*}{ Age } & $<45$ years & 0 & 0 & 5 & 100 & \multirow{3}{*}{0.027} \\
\hline & $\begin{array}{c}45- \\
65 \text { years }\end{array}$ & 18 & 11.9 & 133 & 88.1 & \\
\hline & $>65$ years & 12 & 27.3 & 32 & 72.7 & \\
\hline \multirow[t]{2}{*}{ Sex } & Female & 15 & 17.2 & 72 & 82.8 & \multirow{2}{*}{0.436} \\
\hline & Male & 15 & 13.3 & 98 & 86.7 & \\
\hline \multirow[t]{2}{*}{ Location } & Urban & 13 & 12.7 & 89 & 87.3 & \multirow{2}{*}{0.362} \\
\hline & Rural & 17 & 17.3 & 81 & 82.7 & \\
\hline \multirow{4}{*}{$\begin{array}{l}\text { Edu- } \\
\text { cation }\end{array}$} & $\begin{array}{l}\text { No formal } \\
\text { education }\end{array}$ & 4 & 57.1 & 3 & 42.9 & \multirow{4}{*}{0.000} \\
\hline & Primary & 20 & 33.9 & 39 & 66.1 & \\
\hline & Secondary & 6 & 7.1 & 78 & 92.9 & \\
\hline & $\begin{array}{l}\text { Degree \& } \\
\text { above }\end{array}$ & 0 & 0 & 50 & 100 & \\
\hline \multirow{4}{*}{$\begin{array}{c}\text { Income } \\
\text { (Rs) }\end{array}$} & No income & 10 & 17.9 & 46 & 82.1 & \multirow{4}{*}{0.000} \\
\hline & $<10000$ & 15 & 34.9 & 28 & 65.1 & \\
\hline & $\begin{array}{l}10000- \\
20000\end{array}$ & 5 & 6.8 & 69 & 93.2 & \\
\hline & $>20000$ & 0 & 0 & 27 & 100 & \\
\hline \multirow{3}{*}{$\begin{array}{l}\text { Hyper- } \\
\text { tension } \\
\text { duration }\end{array}$} & $<3$ & 7 & 16.7 & 35 & 83.3 & \multirow{3}{*}{0.929} \\
\hline & $3-5$ & 10 & 15.2 & 56 & 84.8 & \\
\hline & $>5$ & 13 & 14.1 & 79 & 85.9 & \\
\hline . & e 4. Asso & . & wee & en & aph & \\
\hline
\end{tabular}

Analysis of the association between demographic characteristics and stroke awareness is shown in Table -4 and Table-5. Subjects belonging to younger age ( $p$ 0.027), higher level of education ( $p$ 0.000) and higher income ( $p$ 0.000 ) were found to have statistical significant awareness on risk factors as compared to peers.

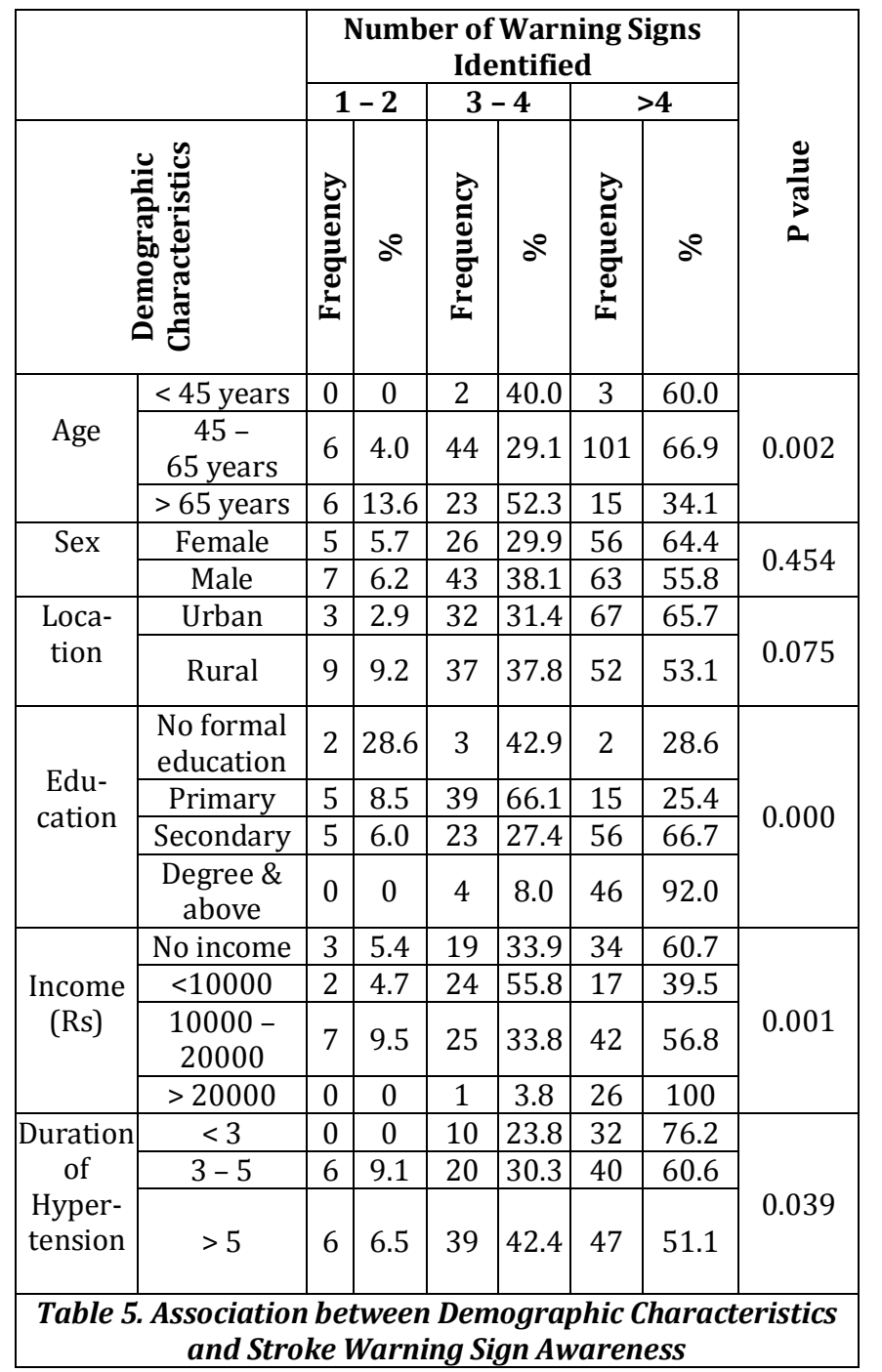

The awareness on warning sign of stroke (Table-5) showed statistically significant association with younger age ( $p$ 0.002), higher level of education ( $p$ 0.000) and higher income ( $p$ 0.001). Subjects with shorter duration of hypertension ( $p$ 0.039) were found to have statistically significant awareness on warning signs than risk factors of stroke.

\section{DISCUSSION}

Studies across India have shown an alarming rise in the incidence of stroke. ${ }^{9-11}$ Inadequate control of modifiable risk factors such as hypertension, diabetes mellitus, dyslipidaemia and smoking were found to be the major cause for this rise.12,13 Awareness on the risk factors of stroke and its optimal management is essential in prevention.

This study was done among individuals with hypertension attending to the out-patient and in-patient services of a tertiary care hospital in Southern India. Their awareness on risk factors and warning signs of stroke were good as compared to similar studies from other geographical areas. Most of such studies were population based and very few were done on subjects who were at higher risk of developing stroke. These studies were based on telephonic interviews from larger population. In the current study, the questionnaire was administered with reasoning by a face-toface interaction. 
We observed $85 \%$ of subjects to identify $>4$ risk factors of stroke. All subjects were able to identify at least one of the risk factors. Similar awareness on risk factors of stroke was observed in hospital based studies done in New Delhi ${ }^{14}$ and Lisbon. ${ }^{15}$ Subjects who did not identify even one risk factor ranged from $6 \%$ to $45 \%$ in various studies from across the world. $16-20$

The risk factor identified by most in the present study was hypertension (94\%); followed by lack of exercise (82.5\%), smoking (81.5\%), diabetes mellitus $(75 \%)$ and stress $(73 \%)$. This observation was consistent with other studies.5,6,8,14-16,19-22 Smoking was the most common risk factor identified in studies from $\operatorname{Iran}^{8}$ and Australia.18 Unhealthy dietary practice was most commonly recognised as a risk factor in a study from Iraq. ${ }^{17}$ Myocardial infarction and/or arrhythmia were poorly identified as risk factors for stroke in the present study. Similar observations were noted in studies from Northwest India, ${ }^{5}$ Iran, ${ }^{8}$ Pakistan, ${ }^{16}$ Australia, ${ }^{18}$ Oman $^{19}$ and Ohio. ${ }^{22}$ Diabetes mellitus is the second most established risk factor for stroke, but this awareness was found to be poor in various studies. $5,15,18,22$

The awareness on well-controlled hypertension and diabetes can prevent stroke was known to $87 \%$ and $79 \%$ of subjects. An interesting observation made was that $42.5 \%$ of the subjects believed stroke to be an unpreventable disease. In a study from Iran, $89.4 \%$ and $35.1 \%$ of subjects felt control of hypertension and diabetes can prevent stroke; and 14.8\% felt stroke as unpreventable. ${ }^{8}$

In the present study, $59.5 \%$ of subjects identified $>4$ warning signs; and $6 \%$ were aware of only 1 or 2 warning signs of stroke. Few studies showed higher8,14 and few showed poor awareness on stroke warning signs. 5,7,16,17,19,22 The most frequent warning sign identified in this study was facial deviation (96\%); followed by difficulty in talking $(80.5 \%)$ and one-sided weakness (73\%). One-sided weakness was identified as a common warning sign of stroke in similar studies.5,8,15,17,19, Our study did not show any significant association between stroke awareness and gender. Few studies had reported gender bias in stroke awareness. $5,16-18,21,22$

Analysis of our data revealed that younger age, higher level of education and higher income had better awareness on stroke risk factors and warning signs. Similar observations were made in earlier studies. 5, 8, 14,15-17, 22

Duration of hypertension had a bearing on awareness of stroke. Present study showed newly detected hypertensives to have more awareness, contrary to similar studies. ${ }^{17,18,21,22}$

The present study showed a good level of awareness on risk factor and warning signs of stroke in comparison to similar studies. Reason for this could be the higher level of education in the study population. Also, this study used a questionnaire with closed-ended questions, which might have overestimated the awareness level. Subjects being hypertensives might have had more visits to healthcare facilities. Their better exposure to preventive aspects of hypertension and stroke as an important complication might have increased their overall awareness.

Interventions at healthcare facilities with stroke units can potentially revert or reduce the stroke morbidity and/or mortality. It is essential that individuals with significant risk factors for stroke to be aware of its symptomatology and seek stroke care at the earliest.23,24

\section{CONCLUSION}

The awareness of risk factors and warning signs of stroke was found to be adequate among patients with hypertension. Stroke is preventable by optimal control of risk factors and early recognition of warning signs. Health care providers need to play an important role in educating patients at high risk for developing stroke. Similar studies can identify the gap in stroke awareness among high-risk patients and could provide useful inputs to stroke prevention programs.

\section{REFERENCES}

[1] Seshadri S, Beiser A, Kelly-Hayes M, et al. The lifetime risk of stroke: estimates from the Framingham study. Stroke 2006;37(2):345-50.

[2] Rothwell PM, Coull AJ, Giles MF, et al. Change in stroke incidence, mortality, case-fatality, severity, and risk factors in Oxfordshire, UK from 1981 to 2004 (Oxford Vascular Study). Lancet 2004;363(9425):1925-33.

[3] Syme PD, Byrne AW, Chen R, et al. Community-based study of stroke incidence in a Scottish population: the Scottish borders stroke study. Stroke 2005;36(9):1837-43.

[4] Feigin VL, Lawes CM, Bennett DA, et al. Worldwide stroke incidence and early case fatality reported in 56 population-based studies: a systemic review. Lancet Neurol 2009;8(4):355-69.

[5] Pandian JD, Jaison A, Deepak SS, et al. Public awareness of warning symptoms, risk factors, and treatment of stroke in northwest India. Stroke 2005;36(3):644-8.

[6] Das S, Hazra A, Ray BK, et al. Knowledge, attitude and practice in relation to stroke: a community-based study from Kolkata, West Bengal, India. Ann Indian Acad Neurol 2016;19(2):221-7.

[7] Onwuka EC, Hemamalini. Assessment of knowledge on risk factors and warning signs of stroke among patients with hypertension in selected village, Kancheepuram District. Int J of Pharma and Bio Scie 2016;6(1):178-84.

[8] Haghighi AB, Karimi AA, Amiri A, et al. Knowledge and attitude towards stroke risk factors, warning symptoms and treatment in an Iranian population. Med Princ Pract 2010;19(6):468-72.

[9] Das SK, Banerjee TK, Biswas A, et al. A prospective community-based study of stroke in Kolkata, India. Stroke 2007;38(3):906-10.

[10] Dalal PM, Malik S, Bhattacharjee M, et al. Populationbased stroke survey in Mumbai, India: incidence and 28-day case fatality. Neuroepidemiology 2008;31(4):254-61.

[11] Sridharan SE, Unnikrishnan JP, Sukumaran S, et al Incidence, types, risk factors, and outcome of stroke in a developing country: the Trivandrum stroke registry. Stroke 2009;40(4):1212-8.

[12] Gupta R, Joshi P, Mohan V, et al. Epidemiology and causation of coronary heart disease and stroke in India. Heart 2008;94(1):16-26.

[13] Kulshrestha M, Vidyanand. An analysis of risk factors and outcomes of cerebrovascular disease in northern India. J Clin Diagn Res 2013;7(1):127-31. 
[14] Monaliza, Meena Aggarwal AS. Awareness of risk factors and warning symptoms of stroke in general population. Nurs Midwifery Res J 2012;8(2):1-8.

[15] Duque AS, Fernandes L, Correia AF, et al. Awareness of stroke risk factors and warning signs and attitude to acute stroke. International Archives of Medicine 2015;8(195):1-18.

[16] Aly Z, Abbas K, Kazim SF, et al. Awareness of stroke risk factors, signs and treatment in a Pakistani population. J Pak Med Assoc 2009;59(7):495-9.

[17] Amen MR. Assessment of hypertensive patients' knowledge about lifestyle risk factors and warning signs of stroke. J Contemp Med Sci 2016;2(5):28-32.

[18] Yoon SS, Heller RF, Levi C, et al. Knowledge of stroke risk factors, warning symptoms, and treatment among an Australian urban population. Stroke 2001;32(8):1926-30.

[19] Al Shafaee MA, Ganguly SS, Al Asmi AR. Perception of stroke and knowledge of potential risk factors among Omani patients at increased risk for stroke. BMC Neurol 2006;6:38.
[20] Falavigna A, Teles AR, Vedana VM, et al. Awareness of stroke risk factors and warning signs in southern Brazil. Arq Neuropsiquiatr 2009;67(4):1076-81.

[21] Pancioli AM, Broderick J, Kothari R, et al. Public perception of stroke warning signs and knowledge of potential risk factors. J Am Med Assoc 1998;279(16):1288-92.

[22] Schneider AT, Pancioli AM, Khoury JC, et al. Trends in community knowledge of the warning signs and risk factors for stroke. JAMA 2003;289(3):343-6.

[23] Davis S, Lees K, Donnan G. Treating the acute stroke patient as an emergency: current practices and future opportunities. Int J Clin Pract 2006;60(4):399-407.

[24] Pandian JD, Kalra G, Jaison A, et al. Factors delaying admission to a hospital-based stroke unit in India. J Stroke Cerebrovasc Dis 2006;15(3):81-7. 